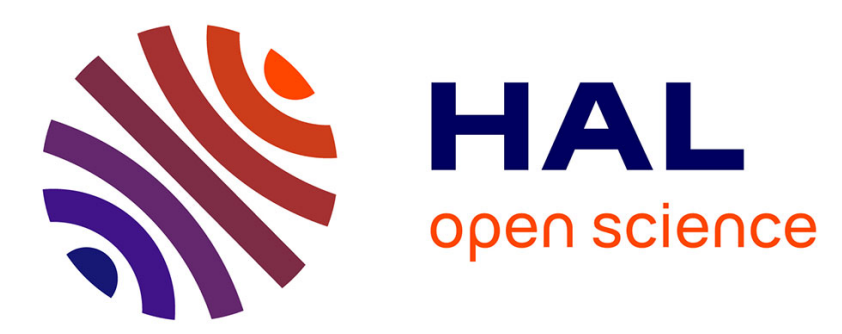

\title{
Synthesis and inkjet printing of sol-gel derived tin oxide ink for flexible gas sensing application
}

\author{
Omar Kassem, Mohamed Saadaoui, Mathilde Rieu, Sergio Sao-Joao, \\ Jean-Paul Viricelle
}

\section{- To cite this version:}

Omar Kassem, Mohamed Saadaoui, Mathilde Rieu, Sergio Sao-Joao, Jean-Paul Viricelle. Synthesis and inkjet printing of sol-gel derived tin oxide ink for flexible gas sensing application. Journal of Materials Science, 2018, 53 (18), pp.12750 à 12761. 10.1007/s10853-018-2577-9 . hal-01823815

\section{HAL Id: hal-01823815 https://hal.science/hal-01823815}

Submitted on 2 Jul 2018

HAL is a multi-disciplinary open access archive for the deposit and dissemination of scientific research documents, whether they are published or not. The documents may come from teaching and research institutions in France or abroad, or from public or private research centers.
L'archive ouverte pluridisciplinaire HAL, est destinée au dépôt et à la diffusion de documents scientifiques de niveau recherche, publiés ou non, émanant des établissements d'enseignement et de recherche français ou étrangers, des laboratoires publics ou privés. 


\title{
Synthesis and inkjet printing of sol-gel derived tin oxide ink for flexible gas sensing application
}

\author{
Omar Kassem ${ }^{1,2}$, Mohamed Saadaoui ${ }^{1}$, Mathilde Rieu ${ }^{2 *}$, Sergio Sao Joao ${ }^{3}$, Jean Paul Viricelle ${ }^{2}$ \\ ${ }^{1}$ Mines Saint-Etienne, Centre CMP, Departement FEL, F - 13541 Gardanne France \\ ${ }^{2}$ Mines Saint-Etienne, Univ Lyon, CNRS, UMR 5307 LGF, Centre SPIN, F - 42023 Saint-Etienne \\ France \\ ${ }^{3}$ Mines Saint-Etienne, Univ Lyon, CNRS, UMR 5307 LGF, Centre SMS, F - 42023 Saint-Etienne \\ France
}

* Corresponding author: Mathilde Rieu, rieu@emse.fr, Tel.: +33477 420282

\begin{abstract}
The fabrication of printed electronic devices based on metal oxide inks requires the formulation of stable suspensions with specific fluidic properties. In our work, a tin oxide based solution was synthetized by aqueous sol-gel method, and transformed into an ink with appropriate viscosity and surface tension to be inkjet-printed on polyimide foil and sintered at relatively low temperature. Thermal analysis by TGA/DSC and microstructural analysis by XRD of synthetized sol show that a crystallized structure of $\mathrm{SnO}_{2}$ could be obtained at $350^{\circ} \mathrm{C}$, which is lower than crystallization temperatures of $\mathrm{SnO}_{2}$ previously reported in the literature, and entirely consistent with the use of polyimide foil. The stability and the rheological properties of the ink were studied to ensure the jettability criteria of the inkjet-printer. Electrical measurements of the printed sensing films were performed to characterize the response to $\mathrm{CO}$ gas in different concentrations, at working temperature of $300^{\circ} \mathrm{C}$.
\end{abstract}

Keywords: $\mathrm{SnO}_{2}$; inkjet printing; printed electronics; flexible substrate; gas sensor 


\section{Introduction}

Flexible electronics holds a prominent position and is expected to meet emerging technological demands and unprecedented applications compared to rigid electronics devices [1, 2]. Particularly, the manufacture of flexible gas sensors based on metal oxide thin film presents an interesting perspective for progress in many fields such as the monitoring of atmospheric environment, the detection of hazardous gases [3, 4] and smart food packaging [5]. However, it is subject to restrictions requiring high operating temperatures which are not compatible with plastic foils.

The use of metal oxides as gas-sensitive material has been widely investigated because of its remarkable sensing properties and the simple sensing mechanism based on changes of conductance in contact with some gases [6]. Metal oxide gas sensors were introduced in the year 1960 by two Japanese researchers: Seiyama who studied the electrical resistance variation of $\mathrm{ZnO}$ for the detection of reducing gases and Taguchi who put in place the first gas sensor based on $\mathrm{SnO}_{2}$ as sensitive material [7]. Among the various types of metal oxide materials, tin dioxide $\left(\mathrm{SnO}_{2}\right)$ has attracted considerable attention, widely used as gas sensor $[8,9]$ because of its high chemical stability, low cost, rapid response and ease of integration during sensor design. $\mathrm{SnO}_{2}$ is an n-type semiconductor with a wide band-gap (3.6eV). The gas sensing mechanism mainly originates from the under-stoichiometric tin oxide state $\left(\mathrm{SnO}_{2-\mathrm{x}}\right)$ when exposed to air [10] due to oxygen vacancies in the crystal structure. Metal oxide could be synthesized by different methods including chemical precipitation [11], hydrothermal method [12], sonochemical process [13], surfactant mediated method [14], radical oxidation [15] and double-phase method [16]. However, in comparison with other chemical routes, the sol-gel technique is relatively simple and inexpensive, and it was widely used for preparation of functional inks $[17,18]$. This technique allows easy control of synthetized oxides and the elaboration of materials in the most varied forms (Thin films, fine powders, fibers, etc). Moreover, it can be operated under low temperatures [19]. 
Once tin oxide based sol is chemically synthetized, it must be deposited onto the foil in order to make a thin film. Many traditional coating techniques have been implemented to prepare sensitive material as thin film including aerosol assisted CVD [20], screen printing [21], spray coating [22] and inkjet printing [18]. In particular, inkjet printing technology is currently attracting a special attention for the manufacture of electronic components [23-26] because this additive technique has the advantage of being fast, accurate and inexpensive, with its compatibility with various substrate and availability of contactless and no-mask patterning [27]. The principle of inkjet printing consists in the formation and the ejection of drops by propagating acoustic pressure waves in the fluid held in a chamber behind the printing nozzle [28]. Nevertheless, challenges remain associated with the control and stability of the jet itself. Undesirable artifacts, such as deviated jets or unwanted generation of additional droplets, also known as satellite drops, can indeed occur and strongly influence the uniformity and the performance of printed components. Therefore, it is crucial to study the stability of the ink and work on the adjustment of its rheological properties to be well printed with high resolution.

In this paper, inkjet was adopted as a deposition technique in order to print a flexible tin oxide gas sensing films. A stable sol was synthetized by sol-gel process, and was used as precursor ink with appropriate viscosity and surface tension. After deposition and curing, a $\mathrm{SnO}_{2}$ film was obtained and its electrical properties as a gas-sensing layer were tested under carbon monoxide injections.

\section{Materials and methods}

\section{Synthesis of $\mathrm{SnO}_{2}$ based sol by aqueous sol-gel route}

The $\mathrm{SnO}_{2}$ sol was prepared using aqueous sol-gel process as described in the literature for the preparation of $\mathrm{SnO}_{2}$ nanopowders [29]. The process consists in dissolving $18 \mathrm{mmol}$ of tin chloride $\left(\mathrm{SnCl}_{2} \mathrm{Sigma}-\right.$ Aldrich) in $100 \mathrm{ml}$ of distilled water. Then, a 25\% ammonia solution $\left(\mathrm{NH}_{3}\right.$ Sigma-Aldrich) was added for complete removal of chloride ions. The addition of $\mathrm{NH}_{3}$ is stopped when the $\mathrm{pH}$ is 9 . A precipitate of tin 
hydroxide was obtained $\left(\mathrm{Sn}(\mathrm{OH})_{\mathrm{n}}, \mathrm{n}=2\right.$ or 4$)$ and separated from the solvent by passing the solution through filter paper on a Büchner funnel and washed several times with diluted ammonia solution. The precipitate was dissolved in glacial acetic acid (Sigma-Aldrich) and ethylene glycol (Sigma-Aldrich) was added in order to form a tin complex. The mixture was heated at $90^{\circ} \mathrm{C}$ and a pale yellow sol containing a complex of tin cations was obtained after 1h (Fig. 1). Tin concentration in the sol was calculated to be $0.13 \mathrm{M}$.
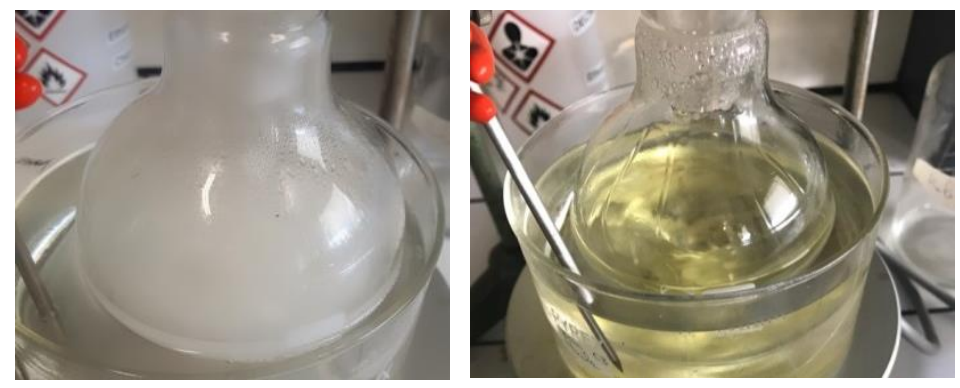

Figure 1 Mixture of tin hydroxide with acetic acid and ethylene glycol before heating (left); after heating (right) at $90^{\circ} \mathrm{C}$

\section{$\mathrm{SnO}_{2}$ ink formulation for inkjet}

We use a commercial lab-scale Dimatix inkjet-printer (DMP-2800, FujiFilm) equipped with a $10 \mathrm{pL}$ cartridge. This printer requires an ink with surface tension in the range of $28-33 \mathrm{mN} / \mathrm{m}$, viscosity in the range of 10-12 mPa.s, and $\mathrm{pH}$ between 4 and 9. Finally, the ink formulation requires particles with diameter smaller than $1 \mu \mathrm{m}$ to avoid nozzles clogging [30].

For ink preparation, solvents mixture was added to the sol in order to adjust its rheology. For homogeneous and stable ink preparation, we used solvents with high boiling temperature $\left(\mathrm{T}_{\mathrm{b}}\right)$ and low vapor pressure $\left(\mathrm{P}_{\text {vap }}\right)$ as ethylene glycol $\left(\mathrm{T}_{\mathrm{b}}=197.3^{\circ} \mathrm{C}, \mathrm{P}_{\text {vap }}=8 \mathrm{~Pa}\right)$ and glycerol $\left(\mathrm{T}_{\mathrm{b}}=290^{\circ} \mathrm{C}, \mathrm{P}_{\text {vap }}=0.4 \mathrm{~Pa}\right)$. Ethanol was then added for adjusting ink surface tension and viscosity. Finally, 2-Isopropoxyethanol surfactant was used for fine-tuning of the surface tension. 
We use the dimensionless parameter $Z$ to quantify the behavior of the ink in the inkjet printer. This dimensionless number is the inverse of the Ohnesorge number $\mathrm{Oh}$, which can be used to measure the ratio between surface tension and viscous forces:

$$
\mathrm{Z}=O \mathrm{~h}^{-1}=\frac{\sqrt{\rho \cdot \gamma \cdot \mathrm{a}}}{\eta}
$$

Where $\rho, \gamma$ and $\eta$ the density, surface tension and viscosity of the fluid, and "a" is a characteristic dimension, i.e., the diameter of the nozzle (DMC-11610 with a nozzle diameter of $21.5 \mu \mathrm{m}$ were used)

The $\mathrm{Z}$ parameter is calculated during ink preparation and it should be between 1 and 10 for successful inkjet printing [28].

\section{Contact electrodes on foil}

A $50 \mu \mathrm{m}$ thick polyimide foil was selected as a substrate (Upilex ${ }^{\circledR}$ S-Goodfellow) because of its high thermal and chemical resistance, and its excellent surface smoothness $(\mathrm{Rz}<60 \mathrm{~nm})$. Prior to processing, the substrate was cleaned by acetone, isopropanol and deionized water then it was dried in an oven at $120^{\circ} \mathrm{C}$ for 30 minutes.

In order to perform electrical measurements, gold electrodes have to be deposited. A $100 \mathrm{~nm}$ thick gold layer was e-beam evaporated onto polyimide (Boc Edwards - Auto 500) with four sources heated by the Joule effect. A $3 \mathrm{~nm}$ thick chromium layer was evaporated prior to gold to act as an adhesion layer.

A $1064 \mathrm{~nm}$ wavelength, pico-second pulsed laser source was used to pattern gold onto foil (Protolaser R, LPKF). Electrodes have width of $1 \mathrm{~mm}$ and space of $500 \mu \mathrm{m}$ and $200 \mu \mathrm{m}$. The laser frequency and power were optimized to $75 \mathrm{KHz}$ and $0.8 \mathrm{~W}$ in order to reduce heat diffusion and to avoid damages at the interface between gold and polyimide. The gold electrodes on foil are presented in Fig. 2. 


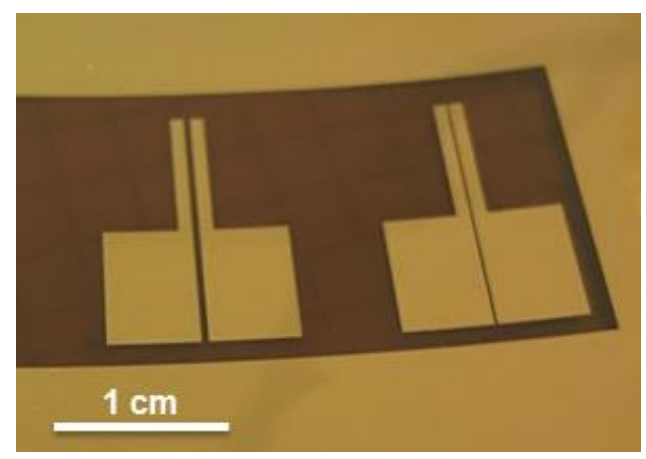

Figure 2 Gold electrodes patterned on plastic foil using laser, with spacing of $500 \mu \mathrm{m}$ (left) and 200 $\mu \mathrm{m}$ (right)

\section{Characterization techniques}

The prepared sol was characterized by dynamic light scattering (DLS) using photocorrelation spectrometer, to estimate the average hydrodynamic size and size distribution of the particles (Malvern Instruments, Malvern, U.K.). For calculation, the refractive index of $\mathrm{SnO}_{2}$ and the room temperature viscosity of the sol were taken at 2.006 and $5 \mathrm{mPa} . \mathrm{s}$, respectively.

Simultaneous thermogravimetric analyses (TGA) and differential scanning calorimetry (DSC) of the $\mathrm{SnO}_{2}$ xerogel (dried sol) was carried out in a Mettler-Toledo TGA/DSC STARe System under 5 L/h air flow at $10^{\circ} \mathrm{C} / \mathrm{min}$. Prior to characterization, the sol was heated at $80^{\circ} \mathrm{C}$ for few hours in standard oven to obtain a xerogel, and then it was placed in open alumina pan crucible.

Surface tension and contact angle measurements were characterized using a goniometer (Apollo Instrument OCA200, Dataphysics). We use Owens-Wendt-Rabel-Kaelble (OWRK) method to determine the surface energy of substrates [31]. This method is based on contact angle measurements of droplets of at least three reference liquids landing on the surface. The surface energy of the solid $\gamma_{S}$ is additively made up of dispersive and polar parts:

$$
\gamma_{S}=\gamma_{S}^{d}+\gamma_{S}^{p}
$$


Where $\gamma_{S}^{d}$ and $\gamma_{S}^{p}$ are the dispersive and polar part of the surface energy, respectively.

$\gamma_{S}$ could be extracted from the equation:

$$
\gamma_{L}(1+\cos \theta)=2 \sqrt{\gamma_{L}^{d} \gamma_{S}^{d}}+2 \sqrt{\gamma_{L}^{p} \gamma_{S}^{p}}
$$

Where $\theta$ is the contact angle between the surface of the substrate and the liquid, $\gamma_{L}$ is the surface tension of the liquid, $\gamma_{L}^{d}$ and $\gamma_{L}^{p}$ are dispersive and polar surface tension of the liquid, respectively [32, 33].

During this work, we use deionized water, diiodomethane, ethylene glycol and a mixture of $40 \%$ ethylene glycol and $60 \%$ (Volume) water to determine the surface energy of substrates. Surface tension values of each liquid are summarized in table 1.

Table 1 Properties of liquids used for contact angle measurements

\begin{tabular}{cccc}
\hline & $\gamma_{L}^{p}(\mathrm{mN} / \mathrm{m})$ & $\gamma_{L}^{d}(\mathrm{mN} / \mathrm{m})$ & $\gamma_{L}(\mathrm{mN} / \mathrm{m})$ \\
\hline Water & 51 & 21.8 & 72.8 \\
Diiodomethane & 0.38 & 50.42 & 50.8 \\
Ethylene Glycol & 21.3 & 26.4 & 47.7 \\
Ethylene Glycol 40\% & 40.04 & 20.25 & 60.29 \\
\hline
\end{tabular}

Structural evolution of $\mathrm{SnO}_{2}$ with temperature was studied using X-ray diffraction recorded on Siemens D5000 at $40 \mathrm{~mA}$ and $40 \mathrm{kV}$ with $\mathrm{Cu}-\mathrm{K} \alpha$ radiation $\left(1.5406 \mathrm{~A}^{\circ}\right)$. Droplets of $\mathrm{SnO}_{2}$ sol were deposited on (111) silicon wafer and then annealed at different temperatures. Diffraction patterns were compared with the reference JCPDS (00-041-1445) and the crystallite size was obtained by the Scherrer formula from the broadening of X-ray diffraction peaks:

$$
D=\frac{0.9 \lambda}{\beta \cos \theta}
$$

Where $\mathrm{D}$ is the crystallite size of crystalline structure, $\lambda$ is the $\mathrm{X}$-ray wavelength $\left(1.5406 \mathrm{~A}^{\circ}\right), \beta$ is the full width at half maximum (FWHM) and $\theta$ is the Bragg angle. 
Atomic force microscopy (AFM) was performed to determine the microstructural properties of the printed film using atomic force microscopy Nanowizard III (JPK Instruments AG, Germany) in the tapping mode. The image was obtained from a $1 \mu \mathrm{m}^{2}$ surface, scanning with 512 by 512 pixels.

Thickness of printed layers was determined by SEM microscopy (Carl Zeiss - Ultra 55). A cross-section of the $\mathrm{SnO}_{2}$ layer was prepared using Broad Ion Beam (BIB) equipment (Ilion Gatan), at a beam energy of $6 \mathrm{keV}$. The thickness was estimated using ImageJ software.

Finally, electrical characterization of the printed sensor was performed using $\mathrm{CO}$ gas, at $300^{\circ} \mathrm{C}$ in dry synthetic air. A cylinder of CO gas (300 ppm, diluted in nitrogen) purchased from Air Product and Chemicals Company was used. The sensor was placed on a heating element equipped with 2 metallic probes in a glass chamber $(500 \mathrm{~mL})$ kept under continuous flowing air at a rate of $15 \mathrm{~L} . \mathrm{h}^{-1}$. The flexible $\mathrm{SnO}_{2}$ gas sensor was stabilized at the operating temperature for a duration between $6 \mathrm{~h}$ and $12 \mathrm{~h}$ before starting $\mathrm{CO}$ injection. A $\mathrm{K}$ type thermocouple (Chromel/Alumel ) was used to control the operating temperature of the sensor. Sensor response measurements, 20 min exposure to CO/air mixture and 35 min recovery in air, were recorded for different concentration from 20 ppm to 100 ppm of CO gas. Gas injections were done using flow meters, and data acquisition was controlled through LabView software.

\section{Results and discussion}

\section{Sol characterization}

The size distribution profile of the sol synthesized at $90^{\circ} \mathrm{C}$ for $1 \mathrm{~h}$ was analyzed by dynamic light scattering (DLS). The average hydrodynamic diameter of the particles was found to be equal to $6 \mathrm{~nm} \pm 3 \mathrm{~nm}$. This result demonstrates the complete peptization of the $\operatorname{Sn}(\mathrm{OH})_{n}$ in acetic acid and ethylene glycol as no aggregation was detected. The presence of aggregation may lead to nozzles clogging during inkjet printing. 
Fig. 3 displays TGA/DSC curves of the $\mathrm{SnO}_{2}$ xerogel. A weight loss of about $88 \%$ is clearly observed between 100 and $210{ }^{\circ} \mathrm{C}$, which can be most likely linked to the evaporation of water molecules, acetic acid $\left(\mathrm{T}_{\mathrm{b}} 118^{\circ} \mathrm{C}\right)$ and ethylene glycol $\left(\mathrm{T}_{\mathrm{b}} 197^{\circ} \mathrm{C}\right)$. This weight loss coincides with two endothermic peaks detected in the DSC curve. The first peak from $90^{\circ} \mathrm{C}$ corresponds to the evaporation of water molecules and bounded acetate groups, and the second one at $200^{\circ} \mathrm{C}$ corresponds to the evaporation of ethoxy bounds that are chemically linked to tin metal according to Köse et al. [29].

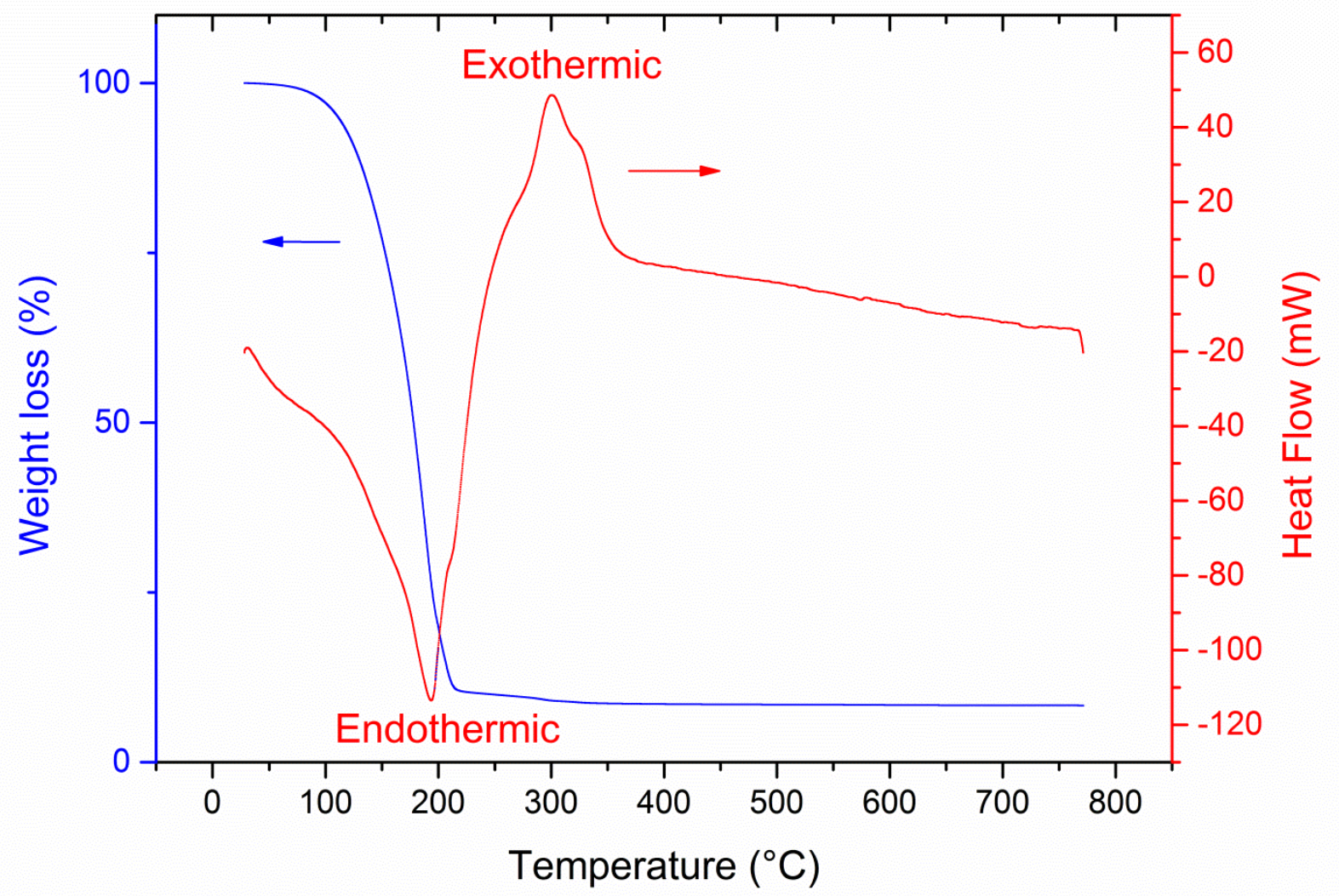

Figure 3 TGA/DSC thermograms of the $\mathrm{SnO}_{2}$ xerogel

In Fig. 4, X-ray diffraction patterns of the sol being annealed at temperatures up to $500^{\circ} \mathrm{C}$ is shown. We can notice that the samples annealed at $200^{\circ} \mathrm{C}$ and $300^{\circ} \mathrm{C}$ are slightly crystalline with an amorphous background. Crystallization of $\mathrm{SnO}_{2}$ occurs at temperature around $350^{\circ} \mathrm{C}$, which is lower than crystallization temperatures of $400^{\circ} \mathrm{C}$ and $500^{\circ} \mathrm{C}$ reported in literature $[18,34]$, making this $\mathrm{SnO}_{2}$ deposit 
compatible with plastic foil. XRD peaks become progressively narrower as the calcination temperature increases. On the other hand, no structural transformation occurred and diffraction peaks can be attributed to the rutile structure. The crystallite size determined by the Scherrer formula was estimated to be approximately $4.5 \mathrm{~nm} \pm 0.1 \mathrm{~nm}$ at $350^{\circ} \mathrm{C}, 4.8 \mathrm{~nm} \pm 0.1$ at $400^{\circ} \mathrm{C}$ and $8.0 \mathrm{~nm} \pm 0.1 \mathrm{~nm}$ at $500^{\circ} \mathrm{C}$, respectively.

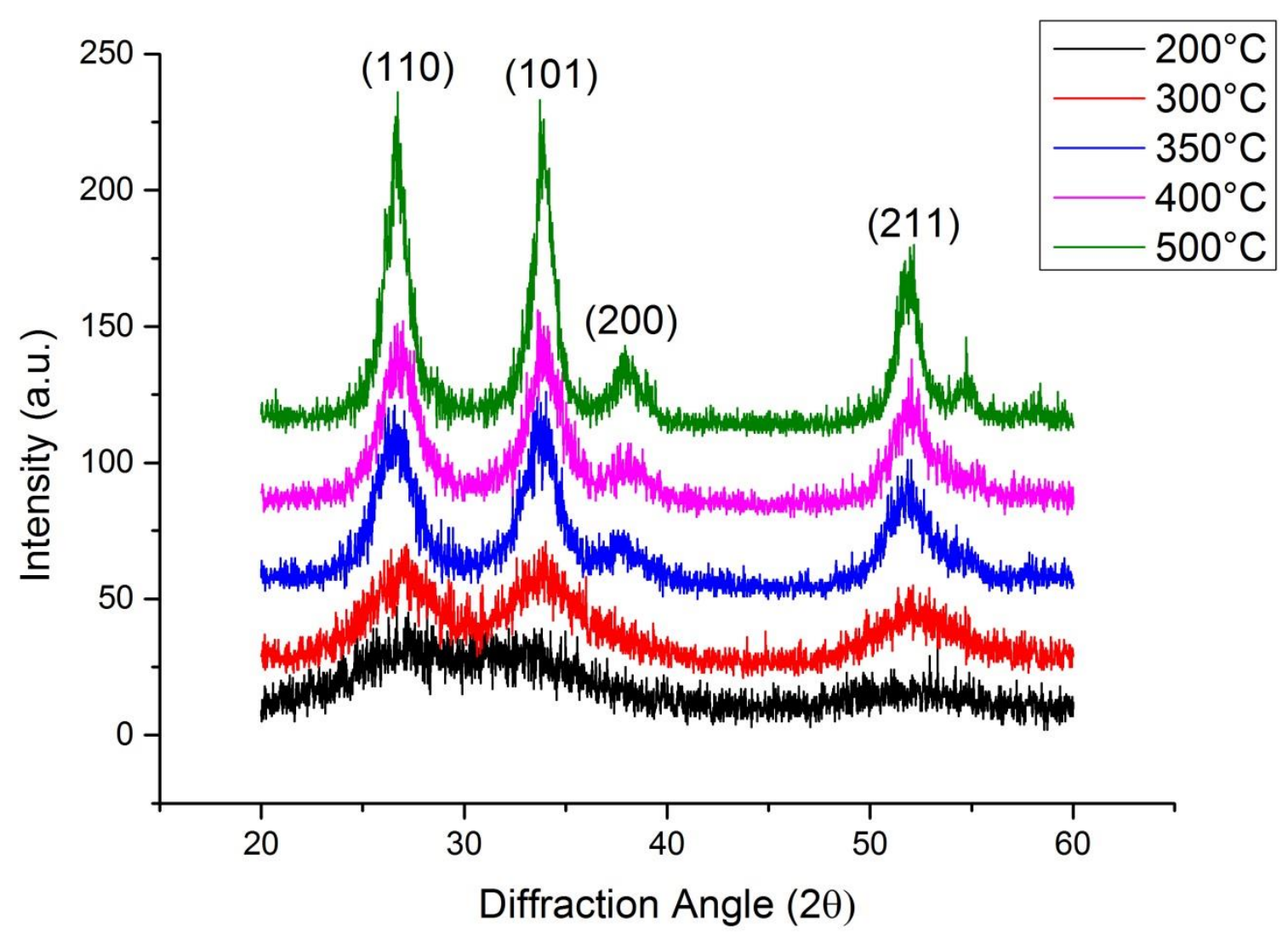

Figure 4 XRD patterns of $\mathrm{SnO}_{2}$ films annealed at different temperatures for 1 hour

\section{$\mathrm{SnO}_{2}$ ink formulation and inkjet printing}

The synthesized tin oxide sol has to be formulated into an ink suitable for inkjet printing. Step one involved the adjustment of the $\mathrm{pH}$ as the synthesized sol is acid with $\mathrm{pH}$ 2.4. This was achieved by stirring the sol at $80^{\circ} \mathrm{C}$ for a few hours to evaporate the majority of the acetic acid, thus increasing the $\mathrm{pH}$ up to 
4-5. The heating temperature was chosen below the boiling temperature of acetic acid in order to avoid aggregation of nanoparticles in the solution.

At this step, the obtained solution is composed of $0.4 \mathrm{M} \mathrm{SnO}_{2}$ in ethylene glycol and residual amount of acetic acid, with a high surface tension of $40 \mathrm{mN} / \mathrm{m}$ and a viscosity of $14.1 \mathrm{mPa} . \mathrm{s}$. First, we added ethanol gradually to adjust ink rheology and we found that ethanol decreases surface tension and viscosity of the ink down to $29 \mathrm{mN} / \mathrm{m}$ and $6.2 \mathrm{mPa} . \mathrm{s}$, respectively. Then, we added glycerol to increase the ink viscosity up to $11 \mathrm{mPa}$.s but glycerol, which has a surface tension $64 \mathrm{mN} / \mathrm{m}$, increased the surface tension of the mixture to $37 \mathrm{mN} / \mathrm{m}$. Finally, the addition of 2-isopropoxyethanol allows fine-tuning of the surface tension to a target value of $32 \mathrm{mN} / \mathrm{m}$. The dimensionless $\mathrm{Z}$ number of the ink is 2.7 indicating good printing quality (target range between 1 and 10). Table 2 summarized final proportions of added solvents and ink properties.

Table 2 proportions of $\mathrm{SnO}_{2}$ ink solvents with rheological properties given at $20^{\circ} \mathrm{C}$

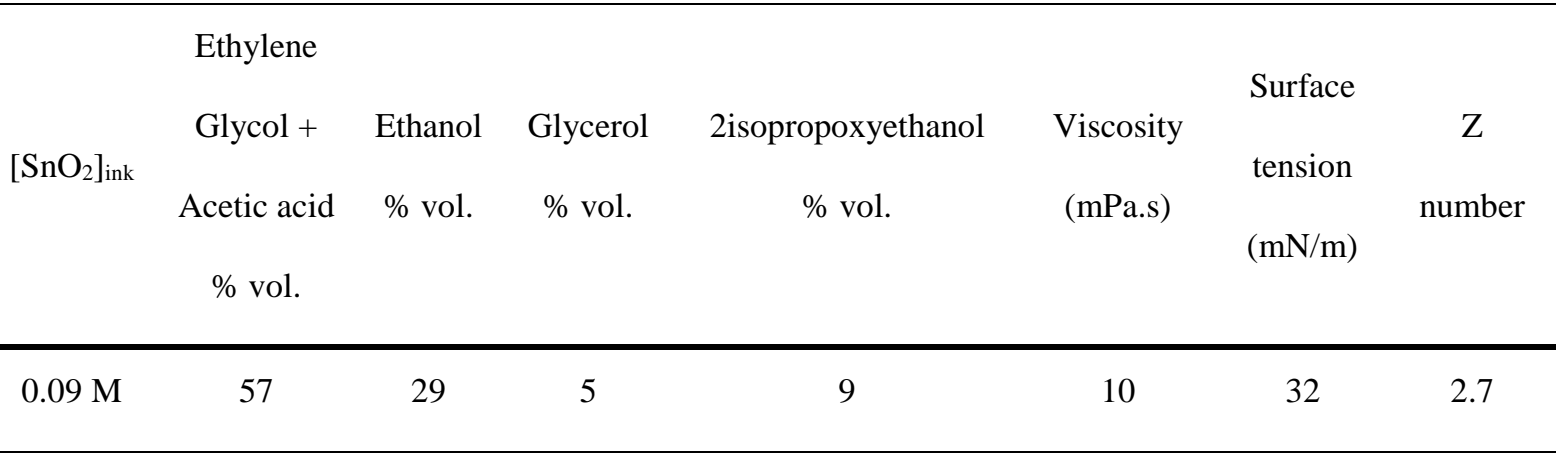

The stability of this ink was maintained over several months if the ink is refrigerated and stored in a closed vessel.

Uniform droplets ejection was successfully achieved with an adjusted waveform using $17 \mathrm{~V}$ as firing voltage and $5 \mathrm{KHz}$ as frequency. The gap between the nozzle and the substrate was maintained at $1 \mathrm{~mm}$. 
Very good ejection quality (Fig. 5) was then achieved with single spherical droplets well oriented vertically.
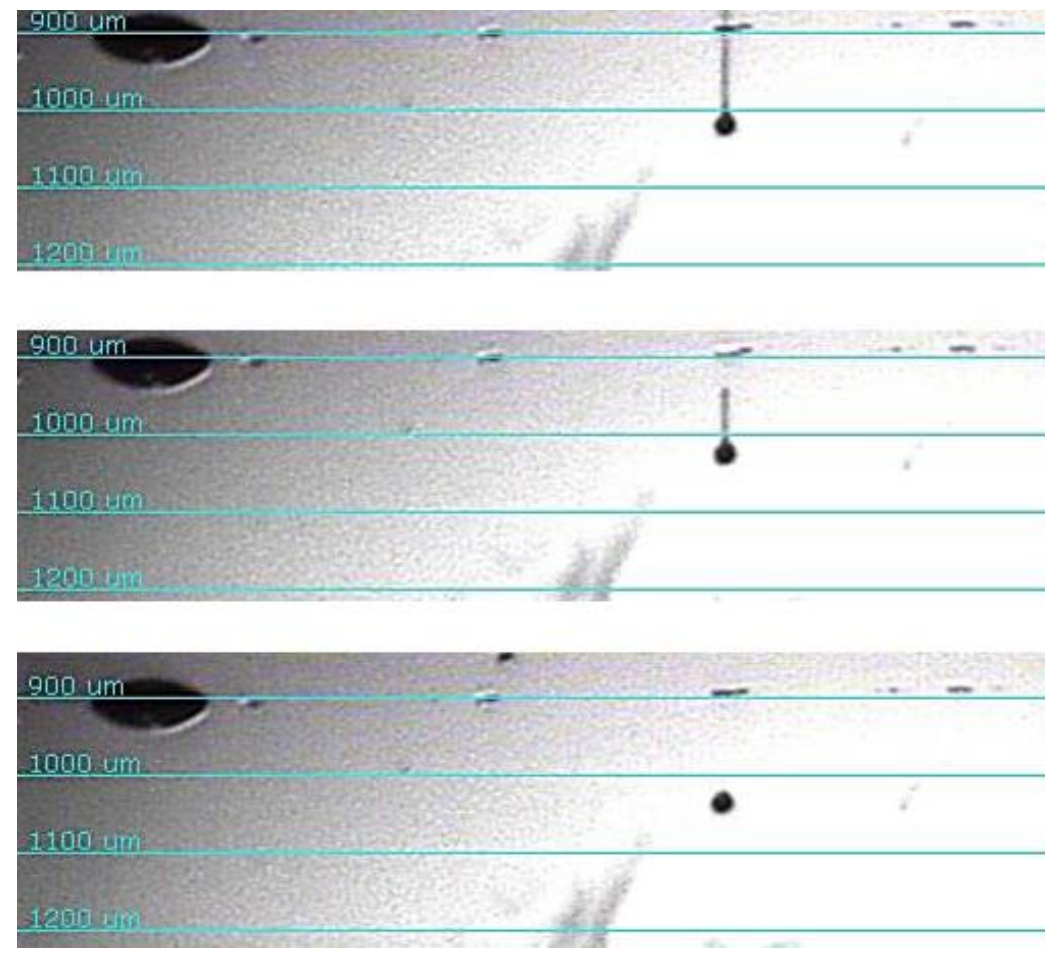

Figure 5 Strobe photographic images showing an ejected drop of $\mathrm{SnO}_{2}$ ink

After adjusting printing parameters, single droplets were printed onto Upilex in order to determine the best drop spacing. The diameter of these drops measured using optical microscope (Nikon Eclipse LV150) was $46 \mu \mathrm{m} \pm 1 \mu \mathrm{m}$ (Fig. 6) and the best drop spacing that gives good surface coverage when printing rectangle was then fixed at $25 \mu \mathrm{m}$. 

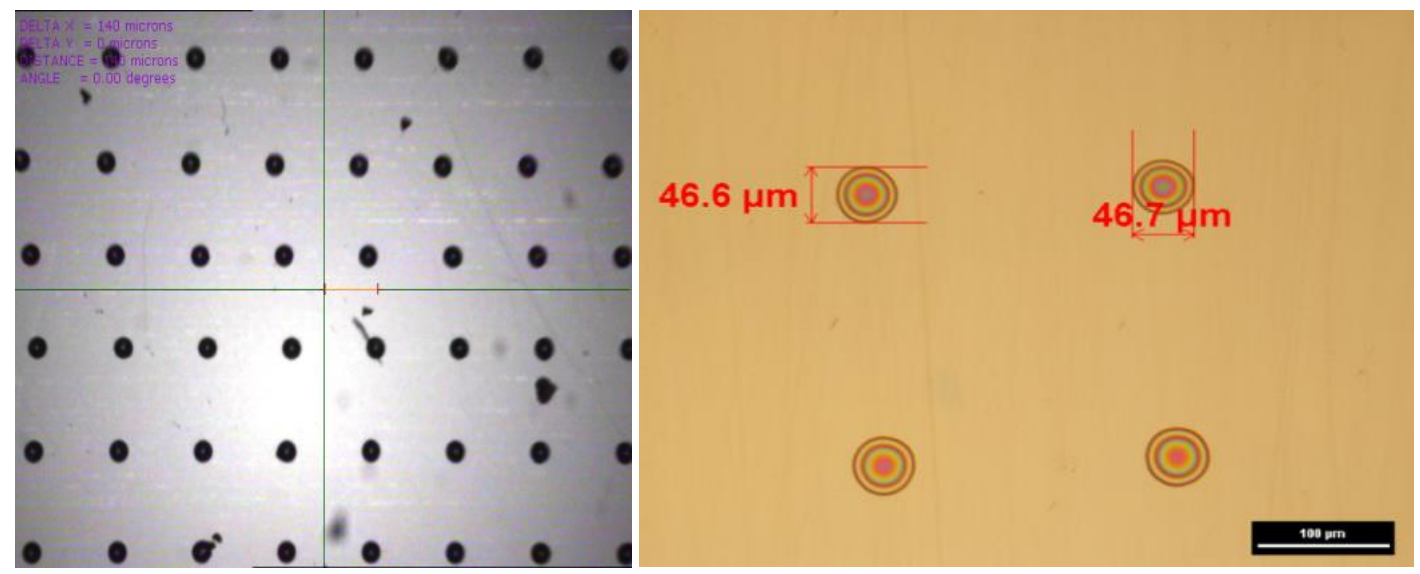

Figure 6 Optical micrograph of $\mathrm{SnO}_{2}$ ink drops printed on Upilex observed by Dimatix printer camera (left) and optical microscope (right)

\section{Substrates surface energy}

For sensor fabrication, $\mathrm{SnO}_{2}$ ink will be printed onto polyimide and over gold electrodes. As the gold will be patterned locally, the surface energy of polyimide after laser treatment was also characterized.

Table 3 summarizes surface energy $\gamma_{S}$ values of materials used in the present study.

Table 3 total surface energy of Upilex and Gold substrate

Substrate $\quad \gamma_{S}(\mathrm{mN} / \mathrm{m})$

Cleaned Upilex

Upilex after laser patterning

Upilex + Evaporated Gold
47

42

38

The surface energy is one of the fundamental parameters controlling the wettability of ink on substrate [35]. The substrate should present a surface energy higher than the surface tension of the ink in order to allow the ink spreading. In our case, the surface energy of gold deposit by evaporation and the cleaned Upilex were measured at $38 \mathrm{mN} / \mathrm{m}$ and $47 \mathrm{mN} / \mathrm{m}$, respectively. The surface energy of Upilex decreases down to $42 \mathrm{mN} / \mathrm{m}$ after laser patterning. The decrease of the surface tension of polyimide could be 
explained by surface roughness, and chemical modifications in polyimide surface after exposure to laser beam $[36,37]$. Surface energies of Upilex and gold are compatible with the surface tension of formulated ink of $32 \mathrm{mN} / \mathrm{m}$. The surface energy of the substrate is great enough to wet and spread the ink without the need of any surface treatment.

\section{Sintering of $\mathrm{SnO}_{2}$ ink}

The sintering temperature of the ink $\left(\left[\mathrm{SnO}_{2}\right]_{\text {ink }}=0.09 \mathrm{M}\right)$ was fixed at $350^{\circ} \mathrm{C}$ for $1 \mathrm{~h}$ (heat rate of $5^{\circ} \mathrm{C} /$ min) in order to crystallize $\mathrm{SnO}_{2}$. The annealing was performed in Rapid Thermal Annealing (RTA) oven (JIPELEC, Jet First). It is well known in the literature that sol-gel solution deposited $\mathrm{SnO}_{2}$ films suffer from pronounced cracks because of capillary forces exerted by the evaporating solvents leading to shrinkage of pores $[38,39]$. In addition, the difference in coefficient of thermal expansion between plastic and $\mathrm{SnO}_{2}$ thin film may also enhance cracks within the film. Both phenomena maybe responsible of tensile stress that generates channeling cracks when its value exceeds the tensile strength of the film. In the literature, successful attempts were conducted to prevent cracks in sol-gel films by reducing the capillary force during drying, using solvents with low surface tension and low evaporation rate like glycerol, N,Ndimethylformamide (DMF) and formamide (FA), and using gels with larger pores [39, 40]. However, this proposal is ineffective when using inkjet because of ink rheological constraints mentioned above.

The top surface views of the samples were examined by an optical microscope (Nikon Eclipse LV150) and a scanning electron microscope (SEM Ultra 55 - Carl Zeiss). Fig. 7 shows the top surface views of different $\mathrm{SnO}_{2}$ films obtained by different conditions: single pass printing, two layers and three layers printed by wet on wet and wet on dry method. The wet on wet method consist in printing a next layer directly after the first one, while in wet on dry method, the first layer is completely sintered at $350^{\circ} \mathrm{C}$ before printing the next one. Figure 8 shows clearly the formed cracks on the surface of the film printed two and three times by wet on wet method. 


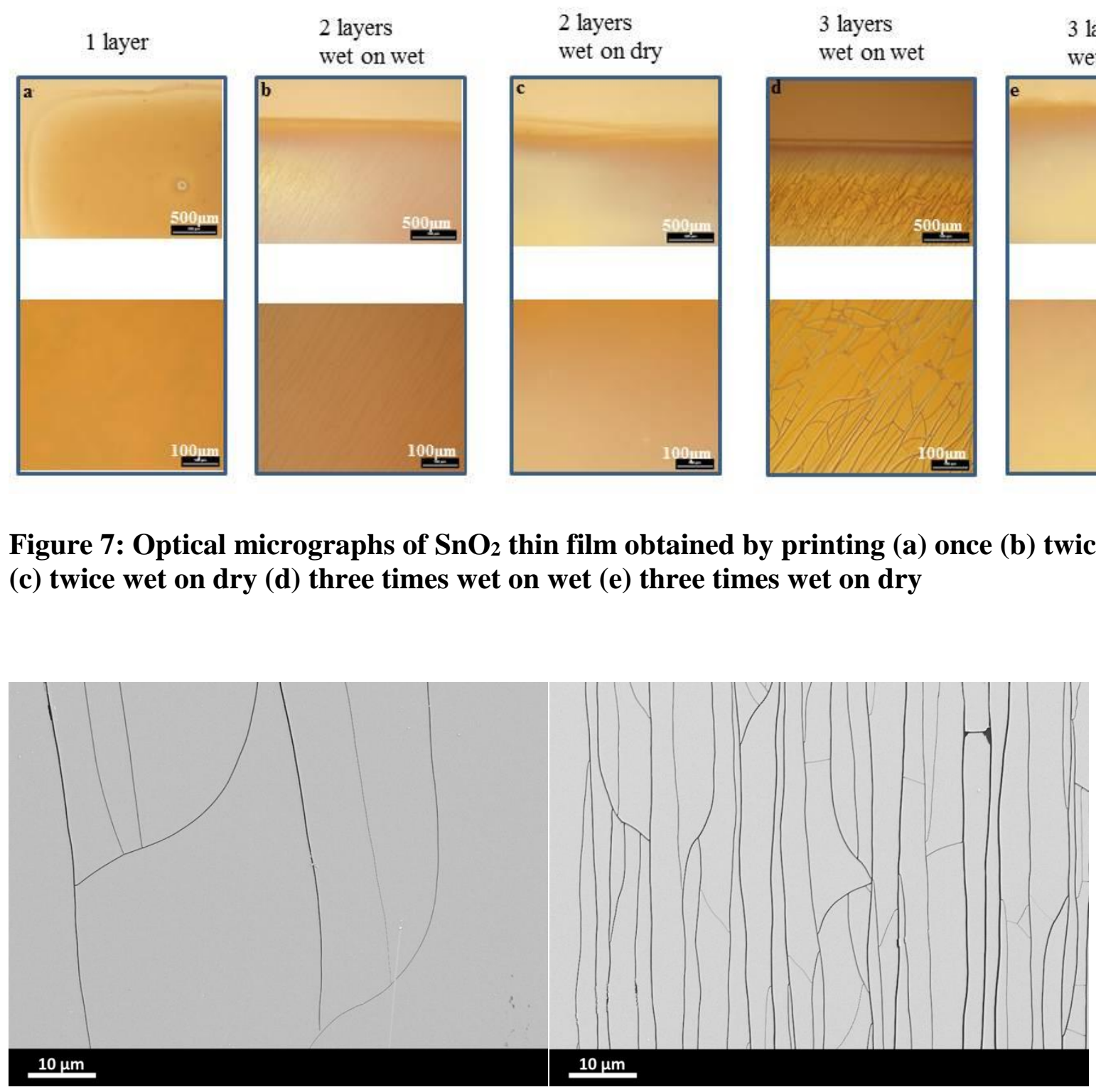

Figure 8: SEM micrographs of the $\mathrm{SnO}_{2}$ film printed two times (left) and three times (right) by wet on wet method on Polyimide and cured at $350^{\circ} \mathrm{C}$

Crack-free $\mathrm{SnO}_{2}$ films were achieved by using a single-print of the ink (Fig. 7a). Cracks number and width increase with the number of printed layers by wet on wet method (Fig. 7b, 7d and Figure 8). Printing more layers leads to larger amount of solvent in the film, and therefore, the capillary forces exerted by the evaporating solvents become more important which induce more retraction and strong cracks propagation [41]. These cracks may raise the resistance of films by altering the electronic conduction path. On the other hand, homogeneous and crack-free film could be obtained by introducing an annealing step at $350^{\circ} \mathrm{C}$ between every single print during multi-pass printing (wet on dry method, Fig. 7c, 7e). In this case, a low 
heating ramp of $5^{\circ} \mathrm{C} / \mathrm{min}$ was used in order to reduce film-drying speed which tends to reduce the capillary force that lead to crack-free films.

The microstructure and the morphology of printed sensing film were extracted from $1.0 \mu \mathrm{m} \times 1.0 \mu \mathrm{m}$ AFM image. Figure 9 shows that the $\mathrm{SnO}_{2}$ printed film, made of nano-sized particles, with size range between 30 and $40 \mathrm{~nm}$, is well uniform and dense without porosity. The surface roughness of the printed film is about $5.5 \mathrm{~nm}$.
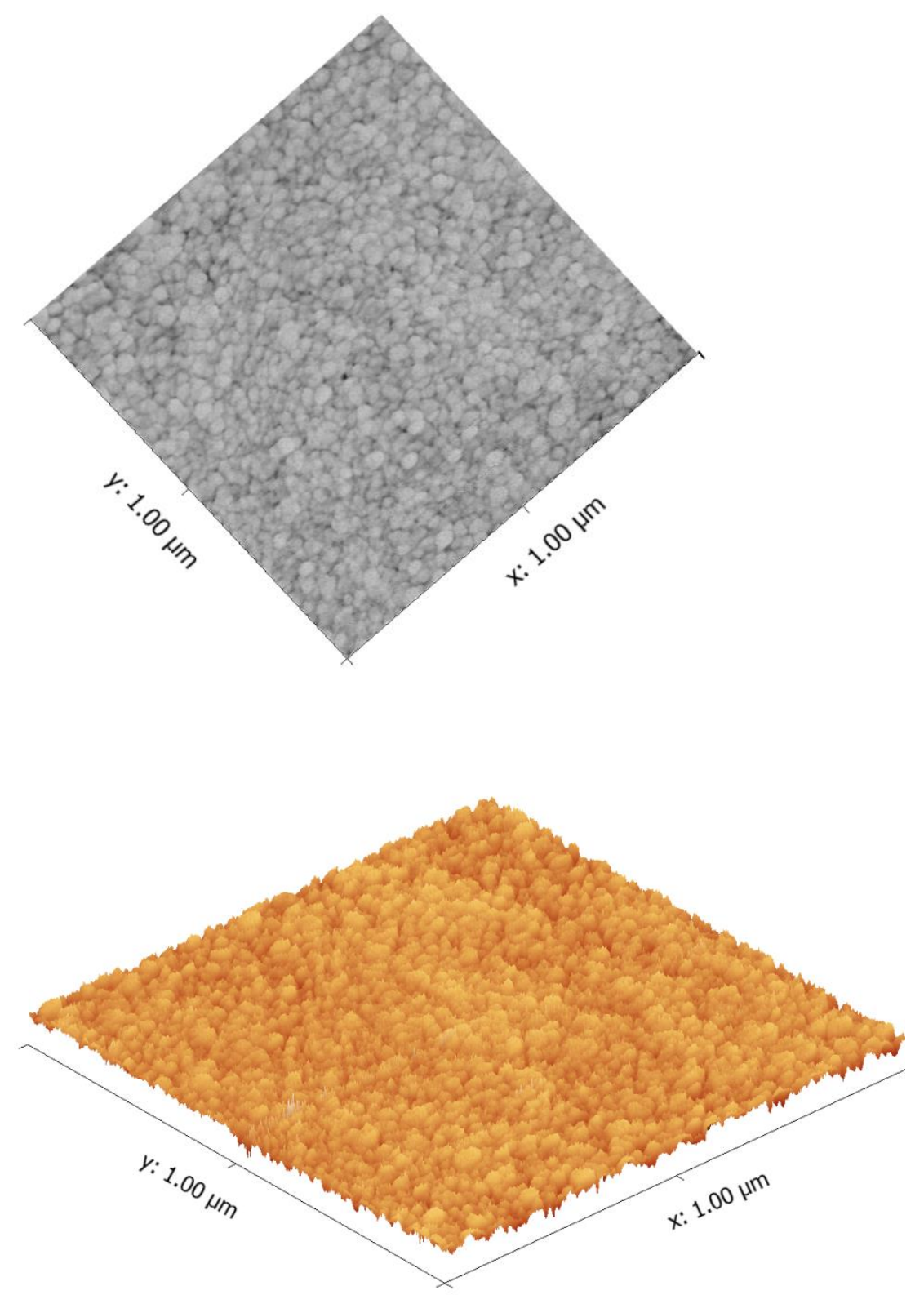

Figure 9: AFM images of the $\mathrm{SnO} 2$ film printed three times by wet on dry method on polyimide and cured at $350^{\circ} \mathrm{C}$ 
A $5 \times 5 \mathrm{~mm}^{2}$ square shape of $\mathrm{SnO}_{2}$ was printed onto Upilex and over gold electrodes 3 times by wet on dry method, and sintered at $350^{\circ} \mathrm{C}$ for $1 \mathrm{~h}$ with heating ramp of $5 \% \mathrm{~min}$. The sensor layout is presented in Fig. 10.

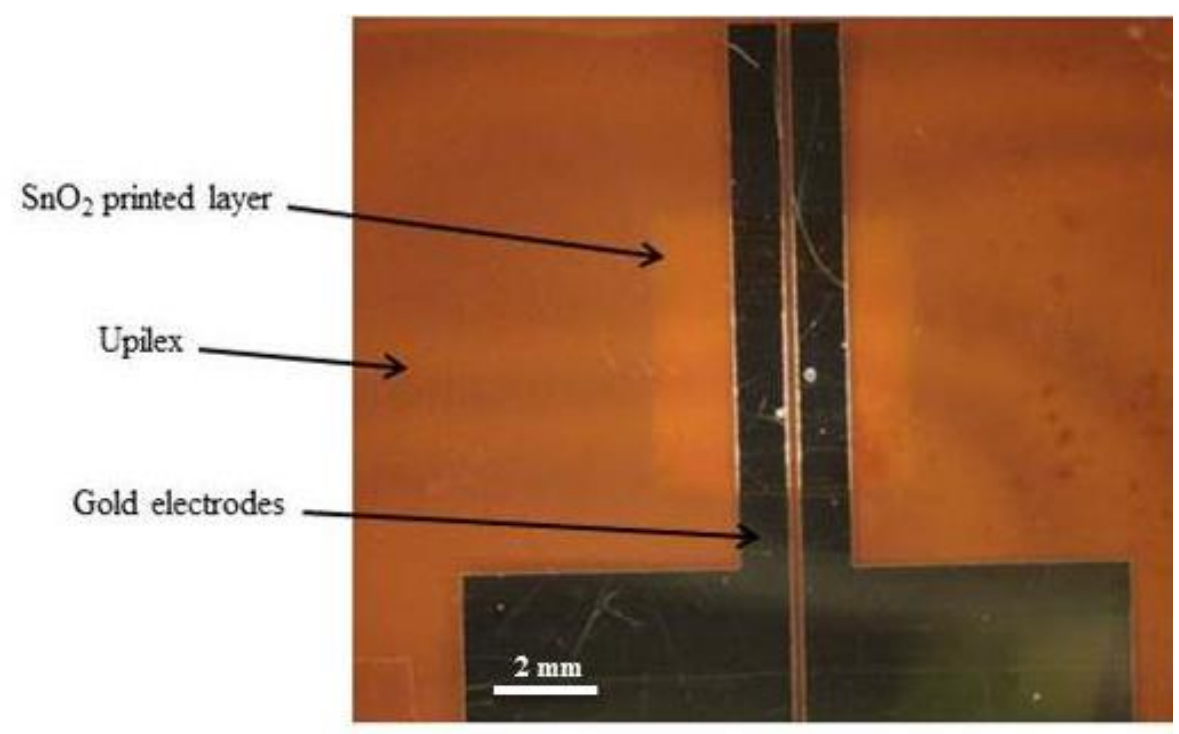

Figure 10: Sensor Layout observed under binocular microscope

Fig. 11 shows cross-section SEM micrographs of triple layer of $\mathrm{SnO}_{2}$ sensor deposited by wet on dry method. The thickness of this layer was about $197 \mathrm{~nm}$.

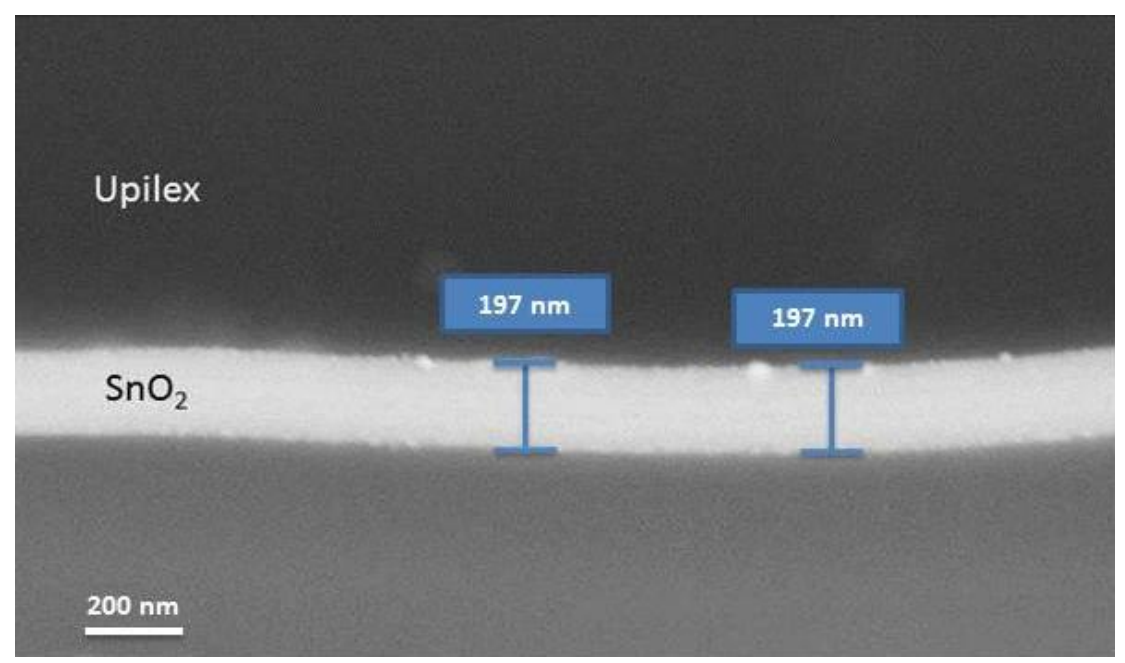

Figure 11: Cross - sectional image of triple layer of wet on dry $\mathrm{SnO}_{2}$ 
Gas sensing application

It should be noted that sensors analyzed in this part are printed by wet on dry method to avoid cracks formation.

The influence of $\mathrm{CO}$ gas on the sensor response was studied at $300^{\circ} \mathrm{C}$. We tested two different sensors containing three layers, with electrodes spacing of $200 \mu \mathrm{m}$ and $500 \mu \mathrm{m}$. These layers were printed annealed at $350^{\circ} \mathrm{C}$ with a low heating ramp as described previously. Fig. 12 shows the response of $\mathrm{SnO}_{2}$. We notice that the conductance of $\mathrm{SnO}_{2}$ increases upon exposure to different concentration of $\mathrm{CO}$ gas (20-100 ppm), and it drops rapidly and returns to its original state when the injection of CO gas is stopped in the testing atmosphere in each cycle, indicating that the gas sensor has reversible response for different $\mathrm{CO}$ concentrations. The change of conductance is mainly due to the interactions between the $\mathrm{CO}$ gas and the surface of the semiconductor sensor. At $300^{\circ} \mathrm{C}, \mathrm{CO}$ gas reacts with the oxygen ions chemisorbed on the surface of $\mathrm{SnO}_{2}$ to form $\mathrm{CO}_{2}$ and release an electron, which leads to an increase of conductance [42, 43]. Once the $\mathrm{CO}$ injection is interrupted, the reaction between $\mathrm{CO}$ and the oxygen ions is stopped, and the conductance returns to its initial state. Consequently, this result demonstrates that the deposited $\mathrm{SnO}_{2}$ layers by inkjet have adequate properties for gas sensing [9].

We notice that the conductance under air increases by decreasing the electrodes spacing. The electrical conductance under air of the sensor with electrodes spacing of $200 \mu \mathrm{m}$ was $4.2 \times 10^{-7} \Omega^{-1}$, while it was $2.6 \times 10^{-7} \Omega^{-1}$ for the sensor with electrodes spacing of $500 \mu \mathrm{m}$. In order to compare the response of these two sensors, we define the normalized sensor response as $\mathrm{G}_{/} \mathrm{G}_{0}$ where $\mathrm{G}$ and $\mathrm{G}_{0}$ are the electrical sensor conductance when exposed to $\mathrm{CO}$ gas and air, respectively. Fig. 13 shows the normalized sensor response as function of $\mathrm{CO}$ concentration (in ppm) when the $\mathrm{SnO}_{2}$ thin film was printed three times, with electrodes space of $500 \mu \mathrm{m}$ and $200 \mu \mathrm{m}$, at an operating temperature of $300^{\circ} \mathrm{C}$. We observe that the response to $\mathrm{CO}$ increases by decreasing the electrodes spacing. With electrodes space of $500 \mu \mathrm{m}$, the response to $40 \mathrm{ppm}$ $\mathrm{CO}$ is 6.3 while it is 7.5 with electrodes space of $200 \mu \mathrm{m}$. This correlation, between the electrodes geometry and the gas sensor performance, is compatible with the results discussed in the literature $[44,45]$. 
We have fixed the electrodes spacing to $200 \mu \mathrm{m}$ and we have tested the sensors made with one and two printed layers (Fig. 14). The conductance of $\mathrm{SnO}_{2}$ increases with the increasing number of layers: the conductance of one, two and three layers of $\mathrm{SnO}_{2}$ when the sensor is exposed to air is about $1.3 \times 10^{-8} \Omega^{-1}$, $2.2 \times 10^{-8} \Omega^{-1}$ and $4.2 \times 10^{-7} \Omega^{-1}$ respectively. As in the case of three layers described previously, the response increases upon exposure to $\mathrm{CO}$ gas and returns to the original value upon exposure to air. Sensor conductance under $\mathrm{CO}$ exposure increases with the number of printed layers. As electrical conductance under air is increased by increasing the film thickness, the conductance measured under $\mathrm{CO}$ is also higher.

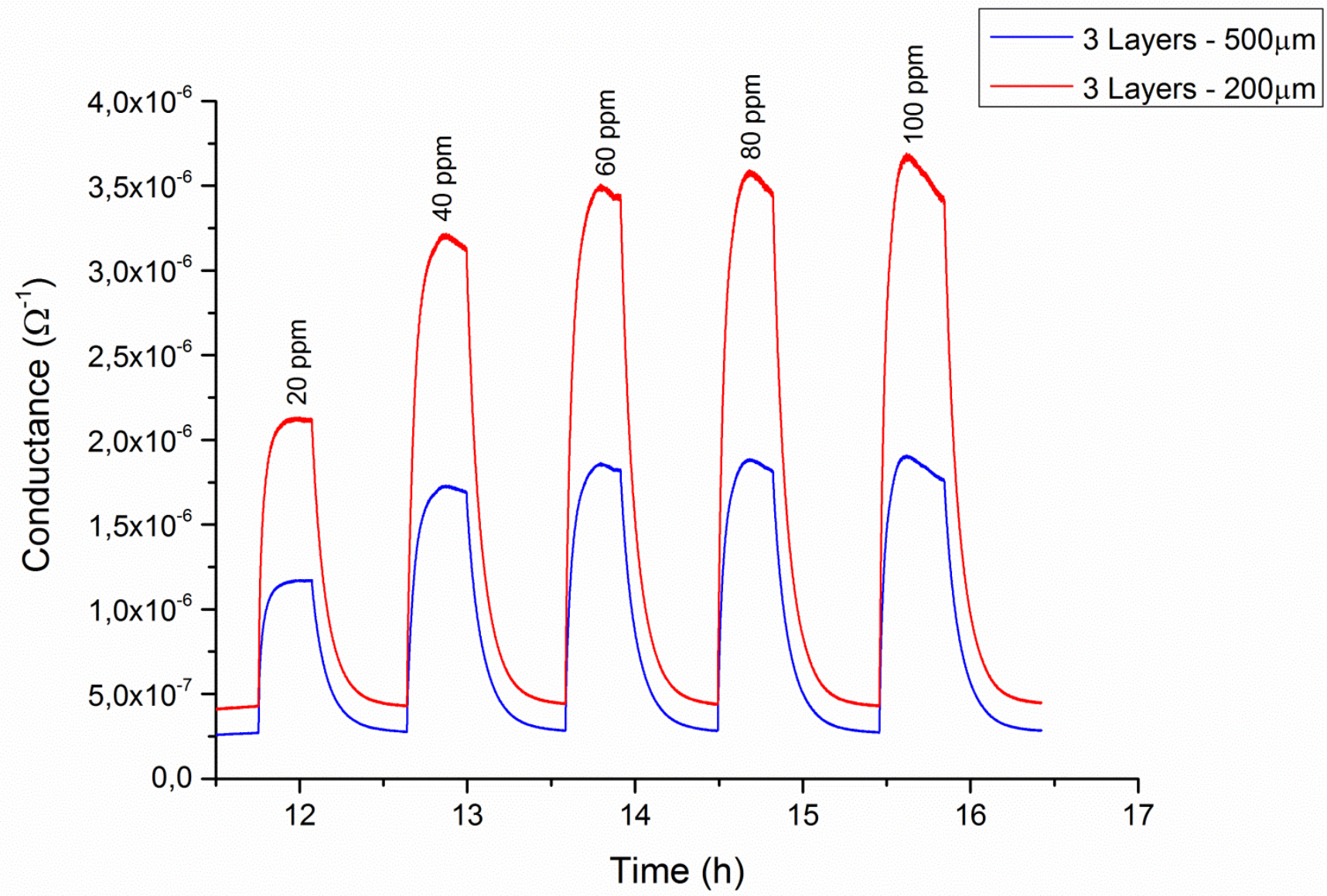

Figure 12: The change of conductance of $\mathrm{SnO}_{2}$ thin film printed three times (wet on dry method), with electrodes spacing of $500 \mu \mathrm{m}$ and $200 \mu \mathrm{m}$, upon exposure to different concentrations of $\mathrm{CO}$ gas at $300^{\circ} \mathrm{C}$ 


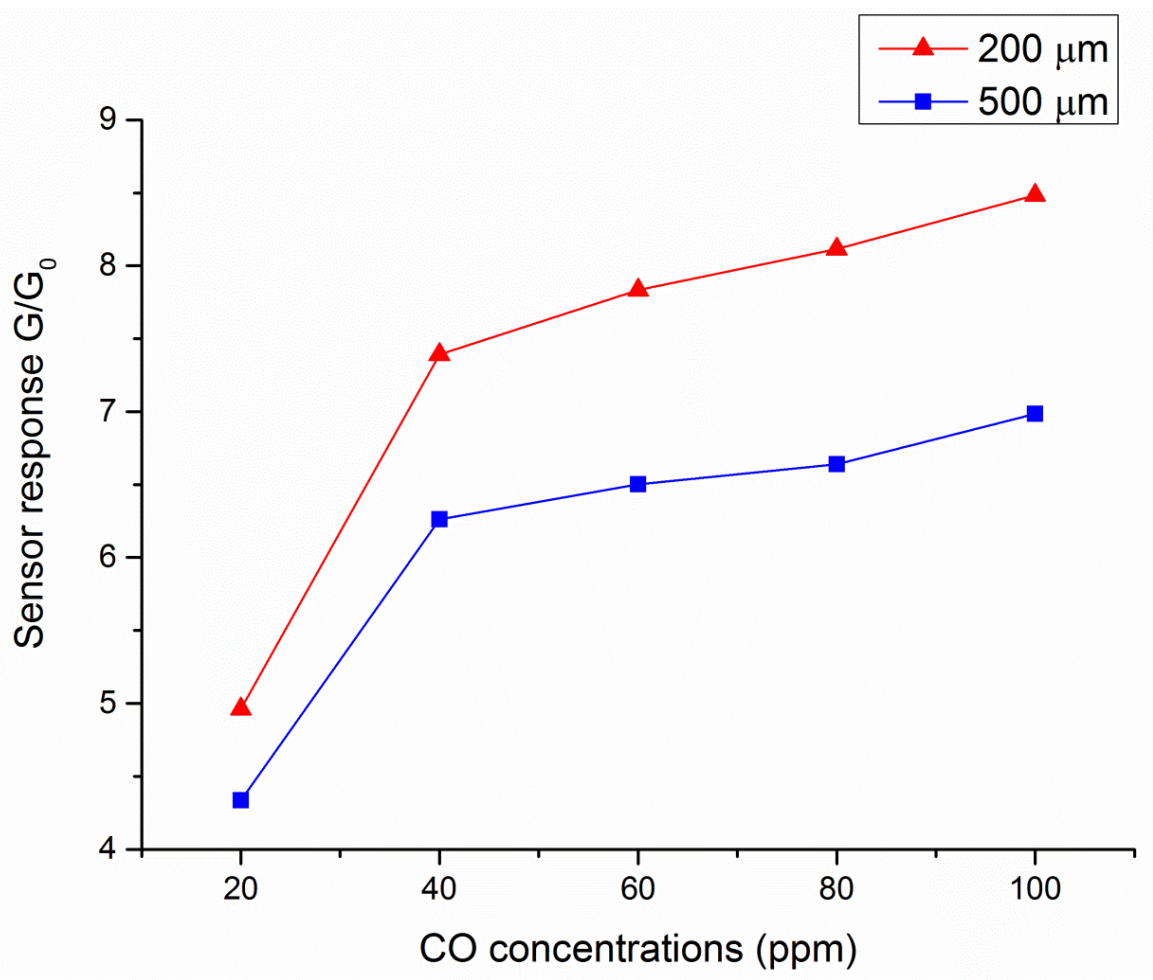

Figure 13: The normalized sensor response of $\mathrm{SnO}_{2}$ thin film printed three times, with electrodes spacing of $500 \mu \mathrm{m}$ and $200 \mu \mathrm{m}$, to different $\mathrm{CO}$ concentrations (20 to $100 \mathrm{ppm})$ at $300^{\circ} \mathrm{C}$

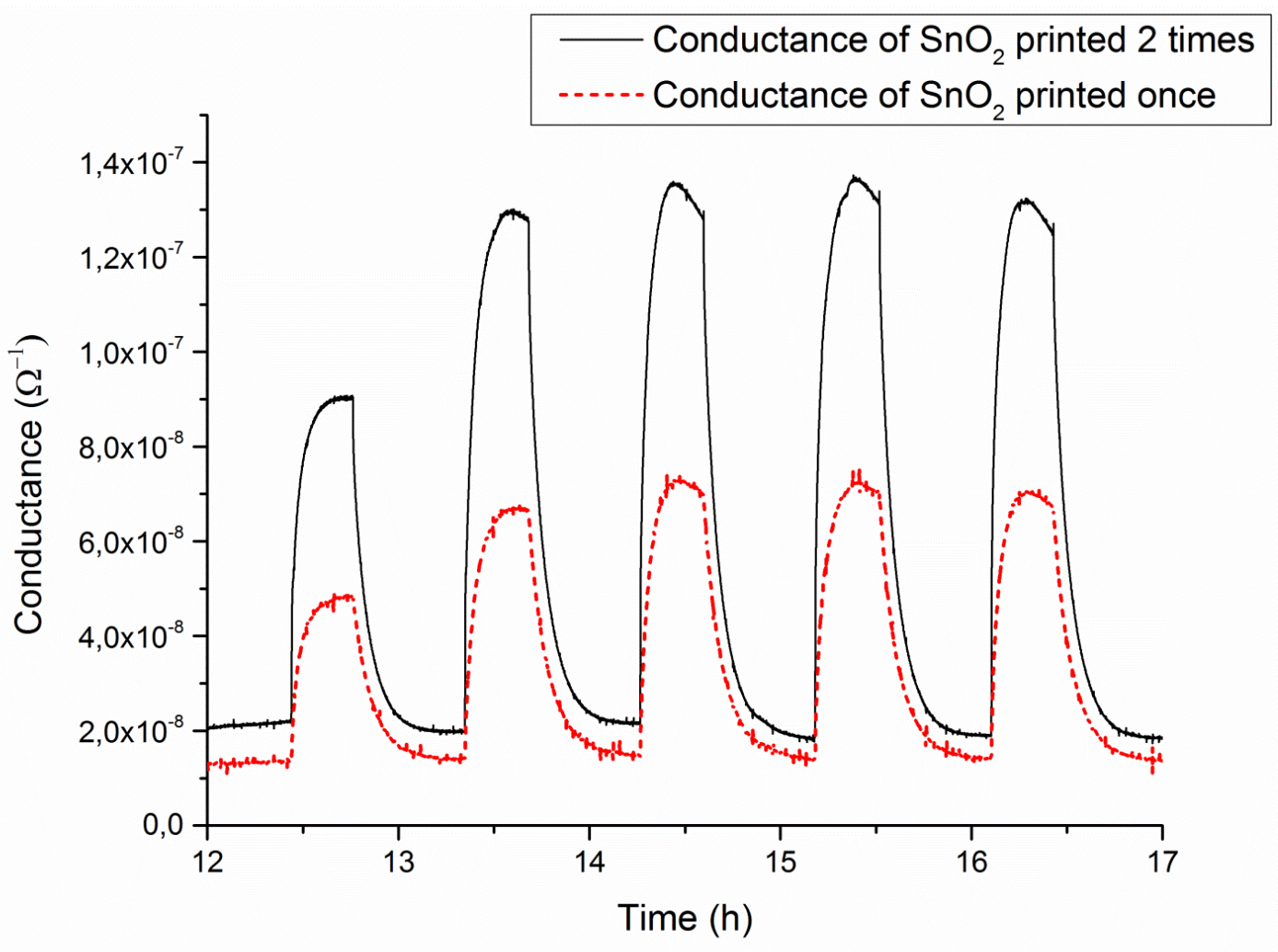

Figure 14: The change of conductance of $\mathrm{SnO}_{2}$ thin film printed once and two times (wet on dry method) upon exposure to different concentrations of $\mathrm{CO}$ gas at $300^{\circ} \mathrm{C}$ 


\section{Conclusion}

In summary, flexible $\mathrm{SnO}_{2}$ gas sensors were successfully prepared by inkjet printing. $\mathrm{SnO}_{2}$ precursor solution was synthetized using aqueous sol-gel method, and then the solution was transformed into ink with suitable rheological properties by adding some solvents and additives. Thermal analyses by TGA/DSC of synthetized sol have shown that a crystallized structure of $\mathrm{SnO}_{2}$ could be obtained at $350^{\circ} \mathrm{C}$, which is entirely consistent with our plastic substrate. XRD patterns have confirmed the crystallization temperature at $350^{\circ} \mathrm{C}$ and have shown that the synthesized $\mathrm{SnO}_{2}$ corresponds to rutile structure. The sensor electrodes with interspace of $500 \mu \mathrm{m}$ and $200 \mu \mathrm{m}$ were patterned by gold deposition and laser beam, and then $\mathrm{SnO}_{2}$ was printed and heated at $350^{\circ} \mathrm{C}$ for 1 hour. Tests under $\mathrm{CO}$ gas were performed at $300^{\circ} \mathrm{C}$, and the printed sensors show a reversible response at different $\mathrm{CO}$ concentrations.

\section{References}

1. Khan S, Lorenzelli L, Dahiya RS (2015) Technologies for Printing Sensors and Electronics Over Large Flexible Substrates: A Review. IEEE Sens J 15:3164-3185

2. Yan C, Wang J, Wang X, et al (2014) An Intrinsically Stretchable Nanowire Photodetector with a Fully Embedded Structure. Adv Mater 26:943-950

3. Acuautla M, Bernardini S, Gallais L, et al (2014) Ozone flexible sensors fabricated by photolithography and laser ablation processes based on $\mathrm{ZnO}$ nanoparticles. Sens Actuators B Chem 203:602-611

4. Uddin ASMI, Yaqoob U, Phan D-T, Chung G-S (2016) A novel flexible acetylene gas sensor based on PI/PTFE-supported Ag-loaded vertical $\mathrm{ZnO}$ nanorods array. Sens Actuators B Chem 222:536-543

5. Matindoust S, Baghaei-Nejad M, Shahrokh Abadi MH, et al (2016) Food quality and safety monitoring using gas sensor array in intelligent packaging. Sens Rev 36:169-183

6. Wang C, Yin L, Zhang L, et al (2010) Metal Oxide Gas Sensors: Sensitivity and Influencing Factors. Sensors 10:2088-2106

7. Neri G (2015) First fifty years of chemoresistive gas sensors. Chemosensors 3:1-20

8. Choi Y-J, Hwang I-S, Park J-G, et al (2008) Novel fabrication of an $\mathrm{SnO}_{2}$ nanowire gas sensor with high sensitivity. Nanotechnology 19:095508 
9. Li C, Lv M, Zuo J, Huang X (2015) SnO2 Highly Sensitive CO Gas Sensor Based on QuasiMolecular-Imprinting Mechanism Design. Sensors 15:3789-3800

10. Jimenez VM, Mejias JA, Espinós JP, González-Elipe AR (1996) Interface effects for metal oxide thin films deposited on another metal oxide II. SnO2 deposited on SiO2. Surf Sci 366:545-555

11. Fu C, Wang J, Yang M, et al (2011) Effect of La doping on microstructure of SnO2 nanopowders prepared by co-precipitation method. J Non-Cryst Solids 357:1172-1176

12. Supothina S, Rattanakam R, Vichaphund S, Thavorniti P (2011) Effect of synthesis condition on morphology and yield of hydrothermally grown SnO2 nanorod clusters. J Eur Ceram Soc 31:24532458

13. Mosadegh Sedghi S, Mortazavi Y, Khodadadi A (2010) Low temperature CO and CH4 dual selective gas sensor using $\mathrm{SnO} 2$ quantum dots prepared by sonochemical method. Sens Actuators B Chem 145:7-12

14. Ma C, Sun X, others (2002) Preparation and characterization of $\mathrm{SnO} 2$ nanoparticles with a surfactant-mediated method. Nanotechnology 13:565

15. Zang Z, Nakamura A, Temmyo J (2013) Single cuprous oxide films synthesized by radical oxidation at low temperature for PV application. Opt Express 21:11448

16. Zang Z, Tang X (2015) Enhanced fluorescence imaging performance of hydrophobic colloidal $\mathrm{ZnO}$ nanoparticles by a facile method. J Alloys Compd 619:98-101

17. Vidmar T, Topič M, Dzik P, Opara Krašovec U (2014) Inkjet printing of sol-gel derived tungsten oxide inks. Sol Energy Mater Sol Cells 125:87-95

18. Rieu M, Camara M, Tournier G, et al (2016) Fully inkjet printed SnO 2 gas sensor on plastic substrate. Sens Actuators B Chem 236:1091-1097

19. Brinker CJ, Scherer G (1990) Sol-Gel Science The physics and chemistry of sol-gel processing. Brinker, New York

20. Vallejos S, Gràcia I, Figueras E, et al (2014) Microfabrication of flexible gas sensing devices based on nanostructured semiconducting metal oxides. Sens Actuators Phys 219:88-93

21. Dubourg G, Segkos A, Katona J, et al (2017) Fabrication and Characterization of Flexible and Miniaturized Humidity Sensors Using Screen-Printed TiO2 Nanoparticles as Sensitive Layer. Sensors 17:1854

22. Yu X, Zhou N, Han S, et al (2013) Flexible spray-coated TIPS-pentacene organic thin-film transistors as ammonia gas sensors. J Mater Chem C 1:6532

23. Kumashiro Y, Nakako H, Inada M, et al (2009) Novel materials for electronic device fabrication using ink-jet printing technology. Appl Surf Sci 256:1019-1022

24. Azzellino G, Grimoldi A, Binda M, et al (2013) Fully Inkjet-Printed Organic Photodetectors with High Quantum Yield. Adv Mater 25:6829-6833 
25. Eggenhuisen TM, Galagan Y, Biezemans AFKV, et al (2015) High efficiency, fully inkjet printed organic solar cells with freedom of design. J Mater Chem A 3:7255-7262

26. Singh M, Haverinen HM, Dhagat P, Jabbour GE (2010) Inkjet Printing-Process and Its Applications. Adv Mater 22:673-685

27. Huang L, Huang Y, Liang J, et al (2011) Graphene-based conducting inks for direct inkjet printing of flexible conductive patterns and their applications in electric circuits and chemical sensors. Nano Res 4:675-684

28. Derby B (2010) Inkjet Printing of Functional and Structural Materials: Fluid Property Requirements, Feature Stability, and Resolution. Annu Rev Mater Res 40:395-414

29. Köse H, Karaal Ş, Aydin AO, Akbulut H (2015) Structural properties of size-controlled SnO2 nanopowders produced by sol-gel method. Mater Sci Semicond Process 38:404-412

30. Hoeng F, Bras J, Gicquel E, et al (2017) Inkjet printing of nanocellulose-silver ink onto nanocellulose coated cardboard. RSC Adv 7:15372-15381

31. Kaelble DH (1970) Dispersion-Polar Surface Tension Properties of Organic Solids. J Adhes 2:6681

32. Owens DK, Wendt RC (1969) Estimation of the surface free energy of polymers. J Appl Polym Sci 13:1741-1747

33. Rudawska A, Jacniacka E (2009) Analysis for determining surface free energy uncertainty by the Owen-Wendt method. Int J Adhes Adhes 29:451-457 .

34. Bagheri-Mohagheghi M-M, Shahtahmasebi N, Alinejad MR, et al (2008) The effect of the postannealing temperature on the nano-structure and energy band gap of $\mathrm{SnO} 2$ semiconducting oxide nano-particles synthesized by polymerizing-complexing sol-gel method. Phys B Condens Matter 403:2431-2437

35. Ely F, Avellaneda CO, Paredez P, et al (2011) Patterning quality control of inkjet printed PEDOT:PSS films by wetting properties. Synth Met 161:2129-2134

36. Bizi-Bandoki P, Benayoun S, Valette S, et al (2011) Modifications of roughness and wettability properties of metals induced by femtosecond laser treatment. Appl Surf Sci 257:5213-5218

37. Lu Q-H, Li M, Yin J, et al (2001) Polyimide surface modification by pulsed ultraviolet laser irradiation with low fluence. J Appl Polym Sci 82:2739-2743

38. Hench LL, West JK (1990) The sol-gel process. Chem Rev 90:33-72

39. Shiomi H, Kakimoto C, Nakahira A, Takeda S (2000) Preparation of SnO2 monolithic gel by solgel method. J Sol-Gel Sci Technol 19:759-763

40. Kadhim IH, Abu Hassan H (2015) Effects of glycerin volume ratios and annealing temperature on the characteristics of nanocrystalline tin dioxide thin films. J Mater Sci Mater Electron 26:34173426

41. Lee WP, Routh AF (2004) Why Do Drying Films Crack? Langmuir 20:9885-9888 
42. Jin Z, Zhou H-J, Jin Z-L, et al (1998) Application of nano-crystalline porous tin oxide thin film for CO sensing. Sens Actuators B Chem 52:188-194

43. Tiemann M (2007) Porous Metal Oxides as Gas Sensors. Chem - Eur J 13:8376-8388

44. Tamaki J, Miyaji A, Makinodan J, et al (2005) Effect of micro-gap electrode on detection of dilute NO2 using WO3 thin film microsensors. Sens Actuators B Chem 108:202-206

45. Lee S (2017) Electrodes for Semiconductor Gas Sensors. Sensors 17:683 